\title{
Is anastomotic urethroplasty is really superior than BMG augmented dorsal onlay urethroplasty in terms of outcomes and patient satisfaction: Our 4-year experience
}

\author{
Anil Kumar Choudhary, MS, FMAS, ${ }^{*}$ Nawal K. Jha, $M S^{\dagger}$ \\ *Ram Manohar Lohia Hospital, New Delhi, India; 'Rajendra Institute of Medical Sciences, Ranchi, India
}

Cite as: Can Urol Assoc J 2015;9(1-2):E22-6. http://dx.doi.org/10.5489/cuai.2291

Published online January 12, 2015.

\section{Abstract}

Introduction: We analyzed the outcomes of augmented buccal mucosa graft (BMG) dorsal onlay urethroplasty and anastomotic urethroplasty in the management of urethral stricture.

Methods: Patients having a stricture length more than $2 \mathrm{~cm}$ were treated by augmented BMG dorsal onlay urethroplasty; patients with a stricture length less than $2 \mathrm{~cm}$ were managed by excision and end-to-end anastomotic urethroplasty. The postoperative retrograde urethrogram, micturating cystourethrogram, and uroflowmetry were compared to preoperative values. The postoperative subjective symptoms and complications were recorded and analyzed. Results: In total, 90 patients were included in this study. Forty-five patients had an average stricture length of $5.9 \mathrm{~cm}$; they underwent BMG augmented dorsal onlay urethroplasty. Of these, 7 (15.55\%) patients came with recurrence, while 38 (84.44\%) were asymptomatic, in the average follow-up period of 32.8 months. The next 45 patients underwent excision of the stricture and end-to-end anastomosis. Of these, 6 (13.33\%) failed on therapy and the remaining 39 (86.66\%) were asymptomatic during the average follow-up period of 28.4 months.

Conclusion: The technique of BMG dorsal onlay is easy to do, it is very reliable, has high success rate, less postoperative complications and better patient satisfaction compared to anastomotic urethroplasty. Our study has its limitations. Recurrent cases of urethroplasty and hypospadias were excluded from this study. Recurrent stricture cases were eliminated to overcome bias. Cases of hypospadias are still best treated by axial or random penile skin flap as BMG augmentation cannot create a long urethral tube. Based on our 4-year experience, we recommend BMG augmented urethroplasty long and short segment stricture of the urethra.

\section{Introduction}

Urethral stricture is a fibrotic narrowing of the urethra. Fibrosis usually extends into the periurethral corpus spongiosum, causing spongiofibrosis and resulting in urine obstruction and the loss of distensibility of the urethra. The first known case of stricture was Indian pioneer surgeon Shusruta (1000 BC). ${ }^{1}$ In 1984, Auguste Nelaton invented the first vulcanized rubber catheter for urethral dilatation, now known as the Nelaton catheter. ${ }^{1}$ Maisonneuve (1854) and Otis (1872) developed the urethrotome to cut the strictured part of the urethra. ${ }^{2}$ In addition, Sachse (1974) revolutionized the treatment by optical urethrotomy. ${ }^{3}$ Devine and colleagues (1980) in their guest editorial recommended treating partial urethral stricture by dilatation first and, if not relieved, then by visual cold knife internal urethrotomy. ${ }^{4}$ Gonococcal urethral stricture is rare in this era of broad spectrum antibiotics, but infection remains a major cause, particularly from long-term use of an indwelling urethral catheter.

latrogenic strictures are also common, which can be attributed to advancements in endo-urological procedures. Treating urethral stricture is very challenging; treatment has high failure rates and multiple postoperative complications. Excision of the stricture and primary end-to-end anastomosis are preferred for short segment strictures. For long segment strictures, buccal mucosa graft (BMG) augmented dorsal onlay urethroplasty is preferred. Humby was the first to describe the use of BMG for urethral reconstruction. ${ }^{5}$ In spite of the many precautions taken with this technique, the recurrence rate is very high in all types of urethroplasties. Surgeons should know the correct technique, the indications, the advantages and the disadvantages of the different types of urethroplasties. In this study, we assessed the success rate, complications and patient satisfaction after these 2 types urethroplasties over a 4-year follow-up period. 


\section{Methods}

This prospective study was carried out on 104 patients admitted to the Rajendra Institute of Medical Sciences in Ranchi, India in the urology department from November 2008 to December 2013. Informed consent was taken from all patients. We recorded, analyzed and compared patient demographics, diagnostic investigations for the urethral strictures, surgical techniques, preoperative and postoperative uroflowmetry and the postoperative complications.

We excluded 14 patients due to their sex (we only included males), stricture secondary due to penile carcinoma, stricture following partial or total penectomy, recurrent case of stricture after urethroplasty, hypopadias and epipadias. Of these excluded patients, 6 were hypospadias, 3 were recurrent cases of stricture after urethroplasty, 3 were cases of partial penectomy and 2 were female.

The exact length of the stricture and its site were diagnosed with the help of retrograde urethrography (RGU) and micturating cystourethrography (MCU). The Nelaton catheter was used to assess the distal end of the stricture from the external urethral meatus. Patients were divided into 2 groups depending on the length of their stricture: (1) patients with a urethral stricture length of less than $2 \mathrm{~cm}$ and planned for excision of stricture segment and end-toend urethral anastomosis; and (2) patients with a stricture length more than $2 \mathrm{~cm}$ and considered for BMG augmented dorsal onlay urethroplasty. After complete patient workup, they were planned for definitive surgery under combined spinal and epidural anesthesia. Patients were placed in the lithotomy position. A midline perineal incision was made and bifurcated $2 \mathrm{~cm}$ above the anal verge. Subcutaneous tissue divided to expose the bulbospongiousus muscle. The bulbospongiousus muscle divided in the midline to expose the underlying urethra; circumferential mobilization of urethra was then achieved by dissecting the reflection of buck's fascia.

\section{Excision of stricture and end to end anastomosis}

The strictured segment was excised with $5 \mathrm{~mm}$ of normal urethral tissue on either side of the stricture segment. The 2 ends were spatulated and then anastomosed on silicone catheter number-14, by interrupted polyglycolic 6-0 sutures. Spatulation provides a good calibre of urethra for better anastomosis. The aim of our technique was to make a water tight anastomosis so that even a single drop of urine could not leak from the anastomotic site. The mobilized urethra was then hitched to the urethral bed to reduce the tension over the anastomosis site. The silicone catheter was removed on postoperative day 21 , and then the $\mathrm{MCU}$ was done and compared with that of preoperative MCU films.
The uroflowmetry followed. The result was recorded and patient complaints were recorded in the follow-up period.

\section{BMG augmented dorsal onlay urethroplasty}

Buccal mucosa was taken from the mucosal surface of the lower lip. The length of BMG was dependent on the length of stricture. The submucosal layer of fat was completely removed with a fine and blunt dissection and then it was quilted over the dorsal aspect of urethral bed (Fig. 1, Fig. 2 ). The 2 margins of the longitudinally incised strictured segment were stitched with that of the margins of quilted BMG over a silicone Foley catheter size 14 .

All patients were put on suprapubic cystostomy for 2 weeks. After patients received proper bladder training, we removed the silicone Foley catheters on postoperative day 21. MCU was done and compared with preoperative films. Uroflowmetry readings were compared with previous readings. The raw surface created after taking the BMG was left as it was and patients were advised to gargle with antiseptic for 5 days. Patients were allowed orally after 24 hours.

The surgery was considered successful if there were no subjective symptoms; other successful indicators were: a normal postoperative uroflowmetry, normal urethra via the RGU and MCU, and if the Nelaton catheter could be passed into the urethra without obstruction. If these were not present, the surgery was considered a failure. The success rate and the postoperative complications these 2 types of urethroplasty were compared and analyzed.

\section{Results}

A total of 90 patients underwent urethroplasty during the study period and they were followed up for an average of

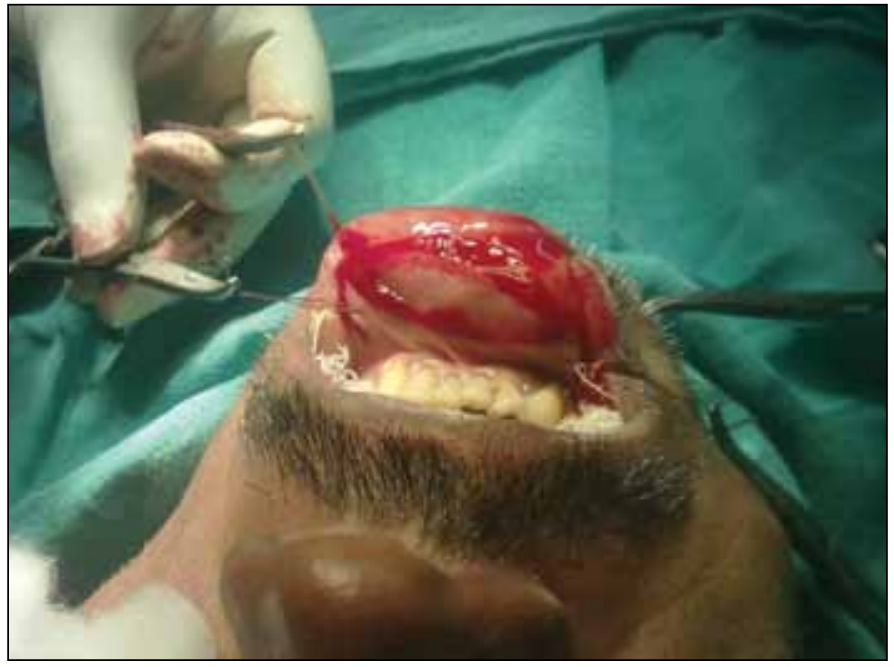

Fig. 1. Showing harvesting of buccal mucosa graft under local anesthesia. 


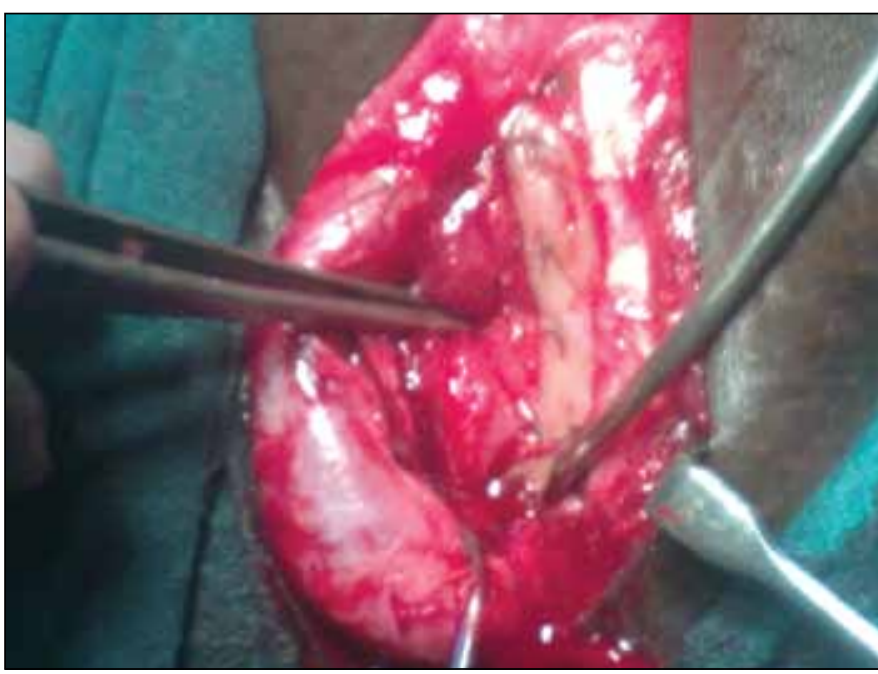

Fig. 2. Showing buccal mucosa graft quilted over the urethral bed.

30.6 months. There were 36 patients $(40 \%)$ between the ages of 21 and 30 and 15 patients $(16.66 \%)$ between the ages of 31 and 40 ; there were 12 patients (13.33\%) between 51 and 60, 9 patients between 41 and 50 years and 3 patients each in group of 61-70 and 71-80 years (Fig. 3).

We found that the main cause of stricture urethra was trauma, either due to road and traffic accidents or endourological procedures. Trauma was the cause in $69(76.66 \%)$, followed by infection in $12(13.33 \%)$ and non-specific causes in $9(10 \%)$ patients. Out of the 69 patients with traumatic urethral stricture, $9(10 \%)$ included patients who had undergone endourological procedures (Fig. 4).

Forty-five patients with an average stricture length of $5.9 \mathrm{~cm}$ underwent BMG augmented dorsal onlay urethroplasty. Of these, $7(15.55 \%)$ had recurrence, while 38 (84.44\%) patients were asymptomatic during an average follow-up of 32.8 months. The other 45 patients underwent excision of the stricture and end-to-end anastomosis. Of these, $6(13.33 \%)$ patients returned after surgical failure and the remaining 39 (86.66\%) patients were asymptomatic during the average follow-up of 28.4 months.

In spite of the longer stricture length (i.e., more than $5.9 \mathrm{~cm})$, the result of BMG augmented urethroplasty had comparable success rates $(84.44 \%)$ to the end-to-end anastomotic urethroplasty $(86.66 \%)$.

Common postoperative complications include a thin stream of urine, incontinence, erectile dysfunction, and chordae (Table 1). Perineal wound infection was seen in a few patients, but this was controlled with proper dressing. There were no significant complications at the site from where the BMG was harvested (Fig. 5).

The exact site of the stricture was accurately calculated by antegrade and retrograde urethral calibration. The location of the stricture was determined by Nelaton catheter calibration. Although RGU and MCU are helpful in diagnosing the stricture site and length, they are not $100 \%$ accurate. Preoperative RGU and MCU findings are at times different.

\section{Discussion}

In the series, 90 male patients with urethral stricture at different levels of etiology were studied. All patients were followed up for an average of 30.6 months. In our study, most patients were in the 21-to-30 age group (40\%). Beard and Goodyear found an incidence of $56.4 \%$ in middle age in a series of 211 patients between the ages of 30 and $50 .{ }^{6}$ In a series of 100 cases, Webster and colleagues found a mean patient age of $47 .^{7}$ Trauma (road and traffic accident and urologic and endourological procedures) constituted $76.66 \%$ of cases in our study. Pelvic bone fractures have contributed to the development of urethral stricture. Sometimes faulty Foley catheterizations and attempts to catheterize a patient with pelvic fractures create a urethral injury. The development of broad spectrum antibiotics has reduced the incidence of urinary tract infections, infective urethritis and its sequel (i.e., stricture). Sometimes the exact cause of urethral stricture is non-specific. Although the diagnosis of urethral stricture is based on RGU and MCU, the Nelaton catheter in our study has helped greatly to locate the distal end of the stricture. The RGU and MCU may be inaccurate due to faulty technique, wrong position of the patient and forceful injection of dye leading to sphincter spasms. Sometimes patients may be hesitant to void during the MCU test, and therefore these results may not be accurate. Stricture urethra can be managed by different modalities of treatments. Urethral dilatation was the first method for relieving partial stricture. Urethrotomy is good for short, single and primary stricture. The overall recurrence rate after the first urethrotomy is $68 \%{ }^{8}$ Repeated urethrotomies do not improve the success rate. Good results can be achieved by urethrotomy if the stricture is single or primary, if it is shorter than $10 \mathrm{~mm}$ and if the calibre is wider than $15 \mathrm{~F} .^{8}$

The most important part of treating a long stricture is augmented urethroplasty. Augmentation can be done with different body tissues, such as the prepuce, skin from the pinna, lingual mucosa, urinary bladder mucosa and buccal mucosa. Among these, BMG has become an ideal urethral

Table 1. Common complications between the 2 patient groups

\begin{tabular}{lcc}
\hline & $\begin{array}{c}\text { Excision and end- } \\
\text { to-end anastomotic } \\
\text { urethroplasty, } \mathbf{n}(\%)\end{array}$ & $\begin{array}{c}\text { BMG augmented } \\
\text { dorsal onlay } \\
\text { urethroplasty, } \mathbf{n}(\%)\end{array}$ \\
\hline Thin stream of urine & $8(17.7 \%)$ & $6(13.33 \%)$ \\
Urinary incontinence & $7(15.55 \%)$ & $2(4.44 \%)$ \\
Erectile dysfunction & $3(6.66 \%)$ & $1(2.22 \%)$ \\
Chordae & $2(4.44 \%)$ & 0 \\
\hline BMG: buccal mucosa graft. & &
\end{tabular}




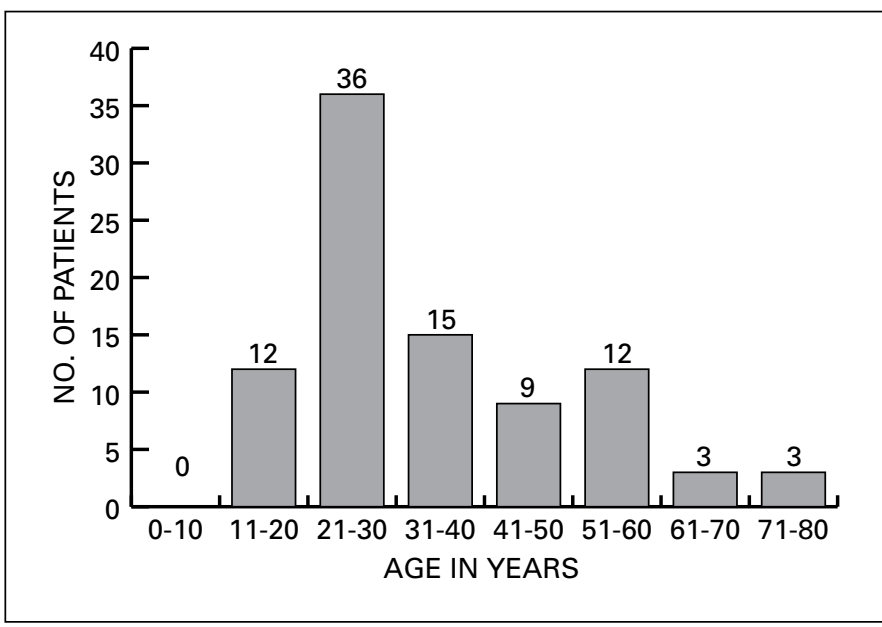

Fig. 3. Age of urethral stricture.

substitute. BMG can be easily harvested under local anesthesia. It is hairless, compatible in a wet environment and is early taken up by the urethral bed. All these unique characteristics make buccal mucosa an integral part of reconstructive urology. In our study, the 2 best techniques (end-to-end anastomosis and BMG dorsal onlay of urethroplasty) were considered.

The success rate of stricture excision and end-to-end anastomosis of the urethra is $86.66 \%$ in this study. In their series of 100 cases stricture of bulbar urethra, Webster and colleagues performed resection and end-to-end anastomosis and recorded a good result. ${ }^{7,9,10}$ They proposed that an anastomosis free of tension could be achieved provided the excision of the stricture was less than $1 \mathrm{~cm}$ long, with appropriate mobilization of urethra. After removing strictured segment, $1 \mathrm{~cm}$ of both ends of the urethra should be obliquely cut. It provides a large caliber for anastomosis, but cutting both ends shortens the length by $3 \mathrm{~cm}$. Nevertheless, penile chordae should be kept in mind and a shortening of more than $3 \mathrm{~cm}$ should be avoided. It is controversial whether BMG should be placed dorsally or ventrally. In the penile urethra, most experts would place it dorsally. In the bulbar urethra, many experts place it ventrally, or mix ventral, dorsal and even laterally. Multiple studies have shown that both dorsal and ventral-onlay BMG provides good blood supply and mechanical support. Standard bulbar urethroplasties using buccal grafts should have a lifetime success rate approaching 92\%. ${ }^{11,12}$ Barbagli and colleagues showed that success rates are equal between dorsal and ventral BMG. ${ }^{13}$ The success rate for dorsal onlay is between $85 \%$ and $100 \% .^{13-17}$ Ventral-onlay BMG graft placement has comparable success rates ( $84 \%$ to $100 \%$ ). ${ }^{13,18-21}$ Kulkarni and colleagues described a full length pan urethral repair using BMG with a $91 \%$ to $100 \%$ success rate. $22-24$

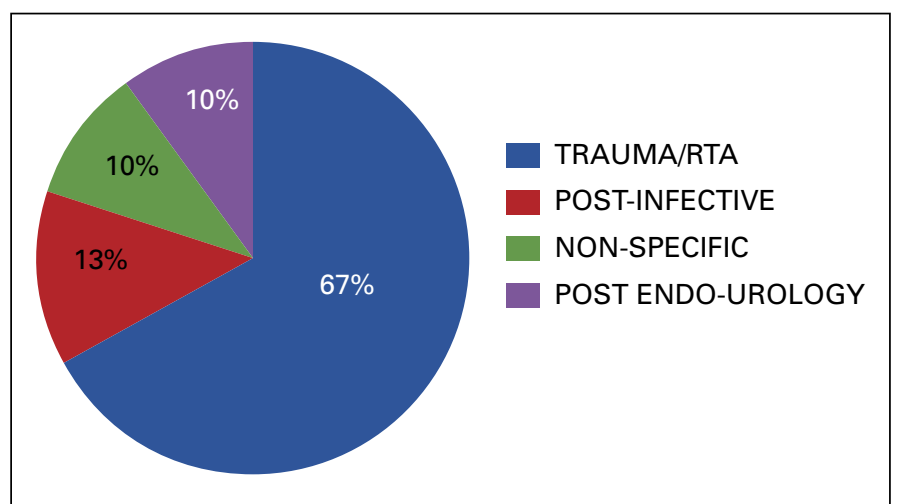

Fig. 4. Etiology of urethral stricture $(n=90)$.

\section{Conclusion}

Comparing the outcomes of both technique, we found that the success rate of anastomotic urethroplasty is almost equal to that of BMG dorsal onlay urethroplasty, but the postoperative complications are more frequent in the anastomotic group. BMG dorsal onlay urethroplasty has given a complication-free life to patients and most were satisfied during follow-up. The technique of BMG dorsal onlay is very easy to do, it is very reliable and it has high success rates. Even in long segment stricture, this is the procedure of choice. Based on our 4-year experience, we recommend BMG augmented urethroplasty for long and short segment stricture of the urethra.

Competing interests: Authors declare no competing financial or personal interests.

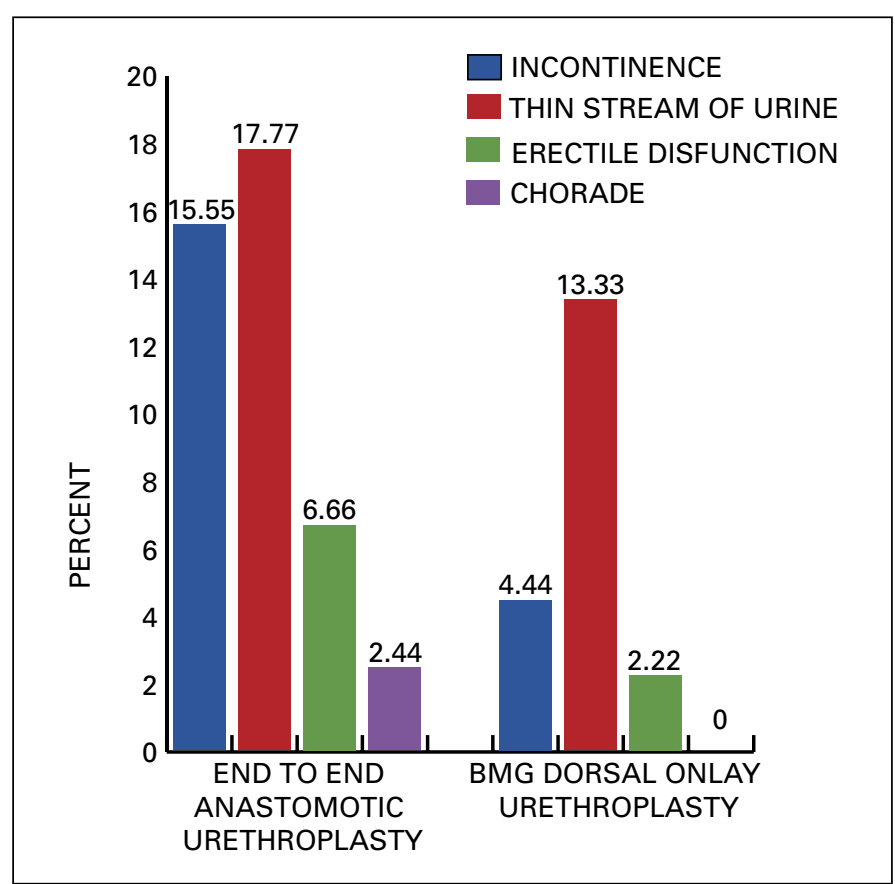

Fig. 5. Postoperative complications of urethroplasty. 
Choudhary and Jha

This paper has been peer-reviewed.

\section{References}

1. Kumar P, Khan M. The history of the catheter from Sushruta to Foley. J Urol 2009;181:386.

2. Matouschek E. Internal urethrotomy of urethral stricture under vision — a five-year report. Urological Res 1978;6:147-50

3. Smith $P$, Dunn $M$, Dounis A. Sachse optical urethrotome in management of urethral stricture in the male: Preliminary communication. J Royal Society Med 1978;71:596.

4. Abdel-Hakem A, Bernstein J, Hassouna $M$, et al. Visual internal urethrotomy in management of urethral strictures. Urology 1983;22:43-5.

5. Humby G. A one-stage operation for hypospadias repair. Br I Surg 1941;29:84-92. http://dx.doi. org $/ 10.1002 /$ bjs. 18002911312

6. Oguike TC, Onuora VC, Obarisiagbon E. The changing pattern of urethral stricture disease in Midwestern Nigeria. JMBR: A Peer-review Journal of Biomedical Sciences 2006;5:50-4.

7. Webster GD, Koefoot RB, Sihelnik SA. Urethroplasty management in 100 cases of urethral stricture: $A$ rationale for procedure selection. J Urol 1985; 134:892-8.

8. Pansadoro V, Emiliozzi P. Internal urethrotomy in the management of anterior urethral strictures: Long-term followup. J Urol 1996;156:73-5. http://dx.doi.org/10.1016/S0022-5347(01)65942-1

9. Park SI, McAninch JW. Straddle injuries to the bulbar urethra: Management and outcomes in 78 patients. J Urol 2004;171:722-5. http://dx.doi.org/10.1097/01.ju.0000108894.09050.c0

10. Koraitim MM. On the art of anastomotic posterior urethroplasty: A 27-year experience. J Urol 2005;173:135-9. http://dx.doi.org/10.1097/01.ju.0000146683.31101.ff

11. Bhargava $S$, Chapple CR. Buccal mucosal urethroplasty: Is it the new gold standard? BJU Int 2004;93:1191-3. http://dx.doi.org/10.1111/j.1464-410X.2003.04860.x

12. Morey AF, McAninch JW. When and how to use buccal mucosal grafts in adult bulbar urethroplasty. Urology 1996;48:194-8. http://dx.doi.org/10.1016/S0090-4295(96)00154-9

13. Barbagli G, Palminteri E, Guazzoni G, et al. Bulbar urethroplasty using buccal mucosa grafts placed on the ventral, dorsal or lateral surface of the urethra: Are results affected by the surgical technique? J Urol 2005;174:955-7. http://dx.doi.org/10.1097/01.ju.0000169422.46721.d7
14. Barbagli G, Palminteri E, Rizzo M. Dorsal onlay graft urethroplasty using penile skin or buccal mucosa in adult bulbourethral strictures. J Urol 1998;160:1307-9. http://dx.doi.org/10.1016/S0022$5347(01) 62522-9$

15. Barbagli G, Selli C, di Cello V, et al. A one-stage dorsal free-graft urethroplasty for bulbar urethral strictures. Br J Urol 1996;78:929-32. htrp://dx.doi.org/10.1046/i.1464-410X.1996.23121.x

16. Dubey D, Kumar A, Bansal $P$, et al. Substitution urethroplasty for anterior urethral strictures: A critical appraisal of various techniques. BJU Int 2003;91:215-8. http://dx.doi.org/10.1046/j.1464410X.2003.03064.x

17. Iselin CE, Webster GD. Dorsal onlayurethroplasty for urethral stricture repair. World J Urol 1998;16:181-5. http://dx.doi.org/10.1007/s003450050049

18. Elliott SP, Metro MJ, McAninch JW. Long-term followup of the ventrally placed buccal mucosa onlay graft in bulbar urethral reconstruction. J Urol 2003;169:1754-7. http://dx.doi.org/10.1097/01. ju.0000057800.61876.9b

19. Heinke $T$, Gerharz EW, Bonfig R, et al. Ventral onlayurethroplasty using buccal mucosa for complex stricture repair. Urology 2003;61:1004-7. http://dx.doi.org/10.1016/S0090-4295(02)02523-2

20. Kane CJ, Tarman GJ, Summerton DJ, et al. Multi-institutional experience with buccal mucosa onlayurethroplasty for bulbar urethral reconstruction. J Urol 2002;167:1314-7. http://dx.doi.org/10.1016/ S0022-5347(05)65289-5

21. Kellner DS, Fracchia JA, Armenakas NA. Ventral onlaybuccal mucosal grafts for anterior urethral strictures: Long-term followup. J Urol 2004;171:726-9. http://dx.doi.org/10.1097/01. ju.0000103500.21743.89

22. Kulkarni $S$, Barbagli $G$, Kirpekar D, et al. Lichen sclerosus of the male genitalia and urethra: Surgical options and results in a multicenter international experience with 215 patients. Eur Urol 2009;55:945-54. http://dx.doi.org/10.1016/i.eururo.2008.07.046

23. Kulkarni SB, Kulkarni IS, Kirpekar DV. A new technique of urethroplasty for balanitisxeroticaobliterans. J Urol 2000;163:352.

24. Kulkarni SB, Kulkarni JS, Kirpekar DV. Full length buccal mucosa dorsal onlay graft urethroplasty for balanitisxeroticaobliterans. Eur Urol 2000;37:157.

Correspondence: Dr. Anil Kumar Choudhary, PO Namkum, Dist-Ranchi, Jharkhand, PIN 834010, India; dranilkumarchoudhary10@gmail.com 